\title{
Molar Incisor Hypomineralization: A Literature Review
}

\section{Sudhir Mittal ${ }^{1}$ \\ Avninder Kaur ${ }^{2}$ \\ Sunila Sharma ${ }^{3}$}

\author{
Aditi Bector ${ }^{4}$ \\ Reetu Singh ${ }^{5}$
}

\begin{abstract}
In this paper, the current knowledge about Molar Incisor Hypomineralization (MIH) is presented. MIH is defined as hypomineralization of systemic origin of one to four permanent first molars frequently associated with affected incisors and these molars are related to major clinical problems in severe cases. The prevalence of MIH in the different studies ranges from 3.6-25\% and seems to differ in certain regions and birth cohorts. Several aetiological factors (for example, frequent childhood diseases) are mentioned as the cause of the defect. Children at risk should be monitored very carefully during the period of eruption of their first permanent molars. Treatment planning should consider the long-term prognosis of these teeth.
\end{abstract}

Keywords: MIH, first permanent molar, hypomineralization.

\section{INTRODUCTION :}

Dental development and mineralization in humans starts before birth and continues to adolescence when the permanent molars complete their mineralization. The first permanent molar is the first tooth in the permanent dentition to mineralize, a process that starts around birth and is completed at approximately three years of age. ${ }^{1}$ Enamel and dentin are formed by secretory cells and the enamel forming cells, the ameloblasts, are highly specialized cells of ectodermal origin. ${ }^{2,3}$ The ameloblast has a limited reparative capacity; therefore disturbances occurring during the mineralization of enamel will remain as permanent marks. Defects in enamel quality or in other dental hard tissues are important implications for the understanding of evolution, function, origin and relation to etiological factors behind developmental disturbances but also how environmental factors may influence on the mineralization of the dental hard tissues.

There are basically two major developmental defects; enamel hypoplasia and hypomineralized enamel. ${ }^{4}$

Enamel hypoplasia is defined as a quantitative defect of enamel surface that is macroscopically detectable. It may occur as pits or rows and the defect might be shallow or deep, local or generally distributed all over the enamel. ${ }^{5}$

Hypomineralized enamel is defined as a qualitative defect, identified visually. The color of the defect may be white, brown or yellow. The thickness of the enamel is normal at time of eruption. A posteruptive breakdown (PEB) may be seen. If PEB occurs, fractured edges are seen.

The term molar incisor hypomineralization (MIH) was introduced in 2001 to describe the clinical appearance of enamel hypomineralization of systemic origin affecting one or more permanent first molars (PFMs) that are associated frequently with affected incisors. ${ }^{6}$ Also referred to as "hypomineralized" PFMs, "idiopathic enamel hypomineralization," 8,9 "dysmineralized" PFMs, ${ }^{10}$ "nonfluoride hypomineralization," 11,12 and "cheese molars," ${ }^{13,14}$ the condition is attributed to disrupted ameloblastic function during the transitional and maturational stages of amelogenesis. ${ }^{8,15}$ The limited prevalence data for $\mathrm{MIH}$ reflects several diagnostic classifcations. Using the criteria of Weerheijm et al, the prevalence ranges from $4 \%$ to $25 \%{ }^{16}$

\section{DIAGNOSIS}

Any examination for MIH should be undertaken on clean wet teeth and the age of 8 years is optimum as at this age all permanent first molars and most of the incisors are erupted. Judgements related to individual teeth (all PFM and incisors) should be recorded, helping in the correct diagnosis of the condition. Diagnostic criteria for hypomineralization of PFMs currently available are the modified defect of dental enamel (DDE) index given by Federation Dentaire International (Table 1) and the criteria of Weerheijm et al (Table 2)

Table 1 : Modified DDE Index (FDI 1992)

\begin{tabular}{|l|l|}
\hline MILD & $\begin{array}{l}<30 \% \text { of the tooth's enamel surface area visibly } \\
\text { disrupted }\end{array}$ \\
\hline MODERATE & $\begin{array}{l}31 \text { to } 49 \% \text { of the tooth's enamel surface area visibly } \\
\text { disrupted }\end{array}$ \\
\hline SEVERE & $\begin{array}{l}>50 \% \text { of the tooth's enamel surface area visibly } \\
\text { disrupted }\end{array}$ \\
\hline
\end{tabular}


Table 2: Definitions of the criteria used for diagnosing MIH (Weerheijm at al 2001a)

\begin{tabular}{|l|l|}
\hline Criteria & Definitions \\
\hline Opacity & $\begin{array}{l}\text { A defect altering the translucency of the enamel, } \\
\text { variable in degree. The defective enamel is of } \\
\text { normal thickness with a smooth surface and can be } \\
\text { white, yellow or brown in color. The border of the } \\
\text { lesion is demarcated }\end{array}$ \\
\hline PEB & $\begin{array}{l}\text { Posteruptive enamel breakdown. A defect that } \\
\text { indicates loss of surface enamel after tooth eruption, } \\
\text { usually associated with a pre-existing opacity. }\end{array}$ \\
\hline $\begin{array}{l}\text { Atypical } \\
\text { restorations }\end{array}$ & $\begin{array}{l}\text { Size and shape of restoration do not confirm to } \\
\text { typical restorative characterstics. They frequently } \\
\text { extend to the buccal or palatal smooth surfaces } \\
\text { reflecting the distribution of hypoplastic enamel. }\end{array}$ \\
\hline $\begin{array}{l}\text { Extraction due } \\
\text { to MIH }\end{array}$ & $\begin{array}{l}\text { Absence of molar should be related to other teeth in } \\
\text { dentition. Absence of first permanent molar in a } \\
\text { sound dentition is suspected to have been a MIH } \\
\text { molar. }\end{array}$ \\
\hline
\end{tabular}

\section{DIFFERENTIAL DIAGNOSIS}

Teeth with developmental defects of enamel may present similarly, regardless of etiology, and the development defects of enamel hypoplasia like fluorosis may be confused with MIH. MIH should thus be differentiated with highly prevalent fluorosis and Amelogenesis Imperfecta (Table 3). It can be differentiated from fluorosis as its opacities are demarcated, unlike the diffuse opacities that are typical of fluorosis and by the structure of the enamel (fluorosis is caries resistant and $\mathrm{MIH}$ is caries prone). The cause of fluorosis can mostly, be related to the period in which the fluoride intake was too high. Choosing between amelogenesis imperfecta (AI) and $\mathrm{MIH}$ as a diagnosis seems a matter of definition; it should be stressed that, only in very severe MIH cases, the molars are equally affected and mimic the appearance of AI. Mostly in MIH, the appearance of the defects will be more asymmetrical in the molars as well as in the incisors.

Table 3: Clinical criteria for differentiation between MIH, Amelogeneis Imperfecta and Fluorosis:

\begin{tabular}{|l|l|}
\hline Condition & Findings \\
\hline $\begin{array}{l}\text { Amelogeneis } \\
\text { Imperfecta (AI) }\end{array}$ & $\begin{array}{l}\text { Involves all the teeth, family history is present, teeth } \\
\text { may appear taurodont on radiograph }\end{array}$ \\
\hline Fluorosis & $\begin{array}{l}\text { Diffuse opacities which are caries resistant. Number } \\
\text { of teeth involved depends on the time of exposure. }\end{array}$ \\
\hline $\begin{array}{l}\text { Molar incisor } \\
\text { hypominer } \\
\text {-alization }\end{array}$ & $\begin{array}{l}\text { Involves PFM and incisors, well demarcated } \\
\text { opacities will be present which will be caries prone. } \\
\text { Only severe cases may resemble AI. No appearance } \\
\text { of taurodont on radiograph. }\end{array}$ \\
\hline
\end{tabular}

\section{CLINICAL PRESENTATION :}

$\mathrm{MIH}$ is a hypomineralized defect of the first permanent molars, frequently associated with affected incisors. The number of affected first permanent molars per patient varies from one to four and expression of the defects may vary from molar to molar. Within one patient, intact opacities can be found on one molar, while in another molar large parts of the enamel break down soon after eruption. ${ }^{16} \mathrm{~A}$ clinical classification of the severity of MIH into three categories (levels of severity) has been suggested: mild, moderate and severe. ${ }^{12}$ The risk of defects to the upper incisors appears to increase when more first permanent molars have been affected. ${ }^{17}$ The defects of incisors are usually without loss of enamel substance.

Clinically, the hypomineralized enamel can be soft, porous and look like discoloured chalk or old Dutch cheese. The enamel defects can vary from white to yellow or brownish but they always show a sharp demarcation between the affected and sound enamel. The porous, brittle enamel can easily chip off under the masticatory forces. Sometimes, the loss of enamel (posteruptive enamel breakdown) can occur so rapidly after eruption that it seems as if the enamel was not formed initially. After occurrence of the posteruptive enamel breakdown, the clinical pictures can resemble hypoplasia. In hypoplasia, however, the borders to the normal enamel are smooth, whilst in posteruptive enamel breakdown the borders to the normal enamel are irregular.

MIH molars are fragile, and caries can develop very easily. This problem is aggravated because the children tend to avoid the sensitive molars when brushing their teeth, leading to increased stagnation of food and plaque. The fast caries progression can clinically mask the reason behind the susceptibility for caries (hypomineralisation of the enamel) in these molars. Jälevik and Klingberg [2002] found that, compared with normal molars, MIH molars need ten times more treatment time. ${ }^{18}$

The affected teeth can be very sensitive to a current of air, cold or warm. Even with enamel that has not disintegrated, mechanical stimuli, for instance tooth brushing, may instigate toothache in these teeth. It is believed that there is subclinical pulpal inflammation due to porosity of the enamel which could lead to hypersensitivity.

\section{PREDISPOSING FACTORS:}

Hypomineralization is thought to be due to disturbed resorptive potential of ameloblasts and proteolytic enzyme inhibition leading to protein retention and interference with crystal growth and enamel maturation. Most common 
predisposing factors for disrupted amelogenesis of PFM include systemic and environmental insults influencing natal and early post natal development.

1) Systemic illness: Although a number of etiological factors may contribute to $\mathrm{MIH}$, the threshold level needed to cause enamel defects at sensitive stages of amelogenesis is unknown. ${ }^{20}$ Conditions common in the first 3 years, such as upper respiratory diseases, asthma, otitis media, tonsillitis, chicken pox, measles, and rubella, appear to be associated with $\mathrm{MIH}^{7,13,20}$ Antibiotic usage has also been implicated. Due to the concurrence of disease and antibiotic therapy, however, it is difficult to ascertain whether the MIH was associated with the disease or the antibiotic. ${ }^{20}$ Children with poor general health and systemic conditions are more likely to have developmental defects of enamel. ${ }^{21-}$ ${ }^{22}$ The systemic conditions implicated to date include nutritional deficiencies, brain injury and neurologic defects, cystic fibrosis, syndromes of epilepsy and dementia (Kohlschutter-Tonz syndrome), nephritic syndrome, atopia, lead poisoning, repaired cleft lip and palate, radiation treatment, rubella embryopathy, epidermolysis bullosa, ophthalmic conditions, coeliac disease, and gastrointestinal disorders. ${ }^{21,23-25}$

2) Gestational age: Preterm birth has been associated with increased prevalence of enamel defects, including hypomineralization and hypoplasia in the permanent dentition. ${ }^{24,26-28}$ A study of 32 Finnish children 9 to 11 years old found enamel defects in $36 \%$ of children born full term and $84 \%$ of children born preterm. ${ }^{29}$

3) Affect of low pH: Regulation of $\mathrm{pH}$ during mineralization is considered necessary for normal apatite deposition and crystallite growth. Sui et al reported that reduced enamel matrix $\mathrm{pH}$ disrupted the crystal growth and proteinase function which can result in protein retention and hypomineralization. Speculatively conditions affecting matrix $\mathrm{pH}$ during enamel maturation may predispose MIH. A medical condition affecting the $\mathrm{pH}$ like cystic fibrosis has been found to be associated with MIH.

4) Lack of calcium phosphate: An optimal serum calcium level is important for initial dentin mineralization and proper enamel matrix secretion and mineralization. Impaired calcium metabolism plays a role in development of hypomineralized enamel. Studies using secondary ion mass spectrometry and $\mathrm{x}$ - ray microanalysis revealed that increased severity of hypomineralization correlated positively with increasing carbon concentration and decreasing concentration of calcium and phosphorus. Moreover proteins like amelogenin, ameloblastin and enamelin which are essential for enamel matrix formation all belong to the secretory calcium-binding phosphoprotein gene family and are controlled by vitamin D[10] and also certain proteinases processing amelogenins during enamel mineralization at the secretory and early maturation stages like Enamelysin (MMP-20), is also calcium-dependent matrix metalloproteinase. Hence hypocalcemia in any form can predispose a child to develop MIH.

5) Duration of breast feeding: Associations have been made between the presence of polychlorinated dibenzop-dioxins (PCDDs) in breast milk and enamel hypomineralization in both clinical and laboratory studies. ${ }^{30-32}$ The PCDDs belong to a class of environmental pollutants known as polyhalogenated aromatic hydrocarbons. ${ }^{33}$ Persistence and accumulation of PCDDs in tissue lipids and in the food chain may result in chronic low-level exposure in humans. ${ }^{34}$ The most toxic and widely studied of this general class of compounds is $2,3,7,8$ tetrachlorodibenzo-p-dioxin, which is often called simply "dioxin" and which represents the reference compound for this class of compounds. In infancy, children can be exposed to these compounds mainly via breast-feeding. An infant can get even $25 \%$ of the mother's dioxin load via lactation and the accumulation of dioxins and dioxin-like compounds in fat may prolong the duration of their action.

\section{RISK IDENTIFICATION, REMINERALIZATION,} AND PREVENTIVE MANAGEMENT :

MIH children often experience PFM pain and sensitivity and aesthetic concerns when their incisors are affected. A 6-step management approach is proposed as shown in table $4 .^{35}$ Children at risk for MIH should be identified prior to PFM eruption, based upon a relevant history of putative etiological factors in the first 3 years and from careful study under magnification of the unerupted molar crowns on any available radiographs.

The cariogenicity and erosivity of the child's diet should be assessed and appropriate recommendations made for dietary modification. Thorough oral hygiene should be instituted; this could include a desensitizing toothpaste. 


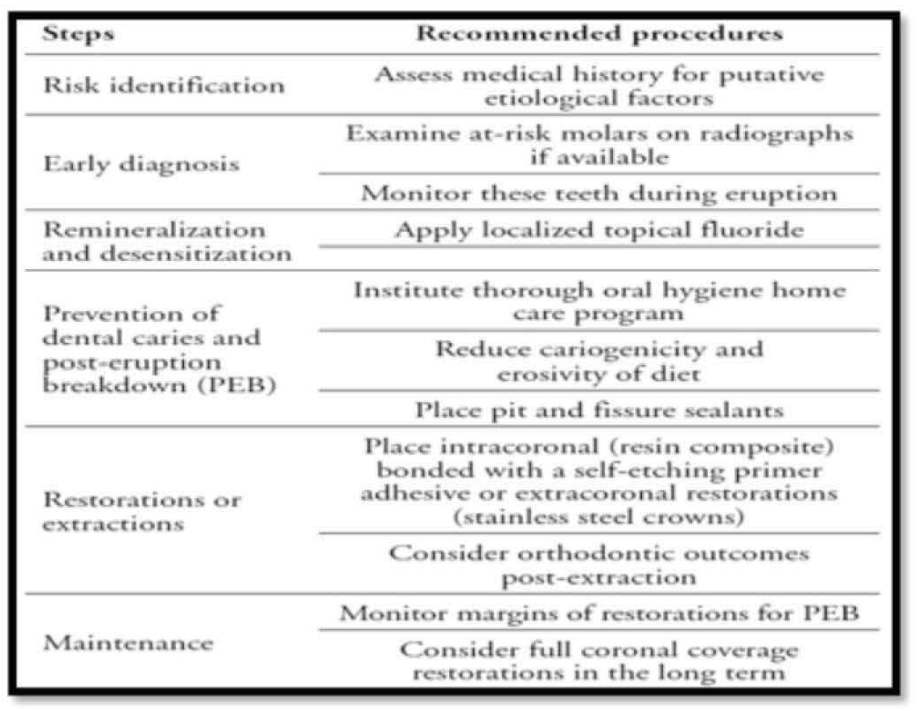

Table 4 - A Clinical management approach for the permanent first molars affected by MIH.

\section{TREATMENT MODALITIES:}

\section{PREVENTIVE:}

.The oral hygiene strategies that could be given to parents or patients in cases where tooth-brushing is difficult due to sensitive, poorly mineralized surfaces of affected molars are as follows:

1. Brush affected molars gently with a desensitizing toothpaste (preferably containing fluoride) on a soft toothbrush;

2. Apply a CPP-ACP topical crème daily using a cotton bud; and

3. Apply a low concentration fluoride treatment gel regularly using a cotton bud.

Remineralization therapy should commence as soon as the defective surface is accessible. Remineralization and desensitization may be accomplished with Topical Fluoride treatment and casein phosphopeptide- amorphous calcium phosphate (CPP-ACP) oral care products is recommended

\section{RESTORATIVE:}

a) Restoration of the permanent first molars : The porous exposed subsurface enamel or dentin may promote chronic inflammation of the pulp, complicating anaesthesia. ${ }^{37,38}$

The choice of materials will depend on the defect severity and the age and cooperation of the child. Adhesive materials are usually chosen due to the atypical cavity outlines following removal of hypomineralized enamel.

With physical properties superior to GIC and RMGIC, the Resin Components are esthetic materials with high wear resistance and adhesion when used with resin-based adhesives.

The RCs are materials of choice in MIH where defective enamel is well demarcated and confined to 1 or 2 surfaces with supragingival margins and without cuspal involvement. Resin composites are not successful in large defects because the etch pattern shows preferential dissolution of rod peripheries, loss of inter rod enamel resulting in enlarged inter rod space and inter crystal space is minimal probably reducing surface area available for bonding. The enamel adhesive interface of hypomineralized enamel is porous with cracks without a uniform hybrid layer. Failures with composite restorations have been thought to be due to these reasons. Hence it is recommended to remove all the hypomineralized enamel prior to placement of resin composite restorations and it is also suggested to pretreat the enamel with $5 \%$ sodium hypochlorite to remove the protein encasing the hydroxyapatite prior to etching.

a) Full coronal coverage restorations : When PFMs have moderate to severe PEB, preformed SSCs are the treatment of choice.

Properly placed, SSCs can preserve PFMs with MIH until cast restorations are feasible.

Compared to SSCs, cast restorations require minimal tooth reduction, provide high strength for cuspal overlay and maintain periodontal health due to their supragingival margins.

b) Restoration of the hypomineralized Permanent incisors : Hypomineralized incisors in MIH may present esthetic concerns to children and their parents. Microabrasion can be an effective treatment in shallow defects, but the defects usually extend through the full enamel thickness.

c) Extraction of severely hypomineralized first permanent molars: When PFMs are severely hypomineralized, restorations may be impossible and extraction must be considered. In such cases, early orthodontic assessment is recommended. Since PFMs are rarely an orthodontist's choice for extraction, later orthodontic treatment may be complicated. Factors affecting molar prognosis-such as vitality and restorability, dental age, buccal segment crowding, occlusal relationships, and the condition of other erupted and unerupted teeth-all need to be assessed when considering molar extraction. If restorative 
treatment is a major problem, or if it fails, the optimal timing of extractions and follow-up of tooth eruption and development of occlusion can be managed.

\section{CONCLUSION}

The prevalence of MIH appears to be increasing, and managing affected children is now a common problem for pediatric dentists. Teeth diagnosed with MIH have significantly lower hardness values (HV) in hypomineralized compared with normal enamel. Although the etiology is unclear and may, in fact, be multifactorial, children born preterm and those with poor general health or systemic conditions in their first 3 years may develop MIH. The early identification of such children will allow monitoring of their PFMs so that remineralization and preventive measures can be instituted as soon as affected surfaces are accessible.

\section{REFERENCES}

1. Reid DJ, Dean MC. Variation in modern human enamel formation times. J Hum Evol. 2006;50:329-46.

2. Simmer JP, Papagerakis P, Smith CE, Fisher DC, Rountrey AN, Zheng $\mathrm{L}$, Hu JC.Regulation of dental enamel shape and hardness.J Dent Res. 2010;89:1024-38.

3. Mahoney P. Two dimensional patterns of human enamel thickness on deciduous (dm1, dm2) and permanent first (M1) mandibular molars. Arch Oral Biol. 2010;55:115-26.

4. FDI Commission on Oral Health Research \& Epidemiology. A review of the developmental defects of enamel index (DDE Index). Commission on Oral Health, Research \& Epidemiology. Report of an FDI Working Group. Int Dent J. 1992;42:411-26.

5. Sabel N, Klingberg G, Dietz W, Nietzsche S, Norén JG. Polarized light and scanning electron microscopic investigation of enamel hypoplasia in primary teeth. Int $\mathbf{J}$ Paediatr Dent. 2010;20:31-6.

6. Weerheijm KL, Jalevik B, Alaluusua S. Molar-incisor hypomineralization. Caries Res 2001;35:390-391.

7. Jalevik B, Noren JG. Enamel hypomineralization of permanent first molars: A morphological study and survey of possible aetiological factors. Int J Paediatr Dent 2000;10:278-289.

8. Fearne J, Anderson P, Davis GR. 3D X-ray microscopic study of the extent of variations in enamel density in first permanent molars with idiopathic enamel hypomineralization. Br Dent J 2004;196:634-638.

9. Koch G, Hallonsten AL, Ludvigsson N, Hansson BO, Holst A, Ullbro C. Epidemiologic study of idiopathic enamel hypomineralization in permanent teeth of Swedish children. Community Dent Oral Epidimiol 1987;15:279-285.

10. Croll TP. Creating the appearance of white enamel dysmineralization with bonded resins. J Esthet Dent 1991;3:3033.

11. Holtta P, Kiviranta H, Leppaniemi A, Vartiainen T, Lukinmaa PL, Alaluusua S. Developmental dental defects in children who reside by a river polluted by dioxins and furans. Arch Environ Health 2001;56:522-528.

12. Leppaniemi A, Lukinmaa PL, Alaluusua S. Nonfluoride hypomineralizations in the permanent first molars and their impact on the treatment need. Caries Res 2001;35:36-40.

13. van Amerongen WE, Kreulen CM. Cheese molars: A pilot study of the etiology of hypocalcifications in first permanent molars. J Dent Child 1995;62:266-269.

14. Weerheijm KL, Groen HJ, Beentjes VE, Poorterman JH. Prevalence of cheese molars in 11-year-old Dutch children. J Dent Child 2001;68:259-262.

15. Wright JT, Hall K, Yamauchi M. The protein composition of normal and developmentally defective enamel. Ciba Found Symp 1997; 205:85-99, 106

16. Weerheijm KL. Molar Incisor Hypomineralization(MIH): Clinical Presentation, Aetiology and Management; Dent Update 2004; 31: 9-12

17. Weerheijm KL, Groen HJ, Beentjes VEVM, Poorterman JHG. Prevalence of cheese molars in 11-year-old Dutch. J Dent Child 2001; 68: 259-262.

18. Jälevik B, Klingberg GA. Dental treatment, dental fear and behaviour management problems in children with severe enamel hypomineralization of their permanent first molars. Int J Paediatr Dent 2002 Jan;12(1):24-32.

19. Lygidakis NA, Dimou G, Marinou D, Gouva G. Aetiology of Molar-incisor Hypomineralization. A retrospective study of 151 children with the defect [abstract]. Barcelona, Spain: 7th Congress of the European Academy of Paediatric Dentistry; 2004.

20. Seow WK. Clinical diagnosis of enamel defects: Pitfalls and practical guidelines. Int Dent J 1997;47:173-182. .

21. Hall R. The prevalence of developmental defects of tooth enamel (DDE) in a paediatric hospital department of dentistry population (part I). Adv Dent Res 1989;3:114-119.

22. Pascoe L, Seow WK. Enamel hypoplasia and dental caries in Australian Aboriginal children: Prevalence and correlation between the two diseases. Pediatr Dent 1994;16:193-199.

23. Seow WK. Enamel hypoplasia in the primary dentition: a review. J Dent Child 1991;58:441-452.

24. Martinez A, Cubillos P, Jimenez M, Brethauer U, Catalan P, Gonzalez U. Prevalence of developmental enamel defects in mentally retarded children. J Dent Child 2002;69:151-155.

25. Kirkham J, Robinson C, Strafford SM, Shore RC, Bonass WA, Brookes SJ, Wright JT. The chemical composition of tooth enamel in junctional epidermolysis bullosa. Arch Oral Biol 2000;45:377-386.

26. Seow WK. A study of the development of the permanent dentition in very low birthweight children. Pediatr Dent 1996;18:379-384.

27. Aine L, Backstrom MC, Maki R, Kuusela AL, Koivisto AM, Ikonen RS, Maki M. Enamel defects in primary and permanent teeth of children born prematurely. J Oral Pathol Oral Med 2000;29:403-409.

28. Seow WK. Effects of preterm birth on oral growth and development. Aust Dent J 1997;42:85-91.

29. Aine L, Backstrom MC, Maki R, Kuusela AL, Koivisto AM, 
Ikonen RS, Maki M. Enamel defects in primary and permanent teeth of children born prematurely. J Oral Pathol Oral Med 2000;29:403-409.

30. Alaluusua S, Lukinmaa PL, Vartiainen T, Partanen M, Torppa J, Tuomisto J. Polychlorinated dibenzo-pdioxins and dibenzofurans via mother's milk may cause developmental defects in the child's teeth. Environ Toxicol Pharmacol 1996;1:193-197.

31. Alaluusua S, Lukinmaa PL, Koskimies M, Pirinen S, Holtta P, Kallio M, Holttinen T, Salmenpera L. Developmental dental defects associated with long breast-feeding. Eur J Oral Sci 1996;104:493-497.

32. Jan J, Vrbic V. Polychlorinated biphenyls cause developmental enamel defects in children. Caries Res 2000;34:469-473.

33. Alaluusua S, Lukinmaa PL, Vartiainen T, Partanen M, Torppa J, Tuomisto J. Polychlorinated dibenzo-pdioxins and dibenzofurans via mother's milk may cause developmental defects in the child's teeth. Environ Toxicol Pharmacol 1996;1:193-197.

34. Gao Y, Sahlberg C, Kiukkonen A, Alaluusua S, Pohjanvirta R,
Tuomisto J, Lukinmaa PL. Lactational exposure of Han/Wistar rats to $2,3,7,8$-tetrachlorobenzo- p-dioxin interferes with enamel maturation and retards dentin mineralization. J Dent Res 2004;83:139-144

35. Vanessa William, DClinDent1 Louise B Messer, Michael F Burrow. Molar Incisor Hypomineralization: Review and Recommendations for Clinical Management. Pediatric Dentistry $-28: 32006$.

36. Fayle SA. Molar incisor hypomineralization: Restorative management. Eur J Paediatr Dent 2003;4:121-126.

37. Jalevik B, Klingberg GA. Dental treatment, dental fear and behaviour management problems in children with severe enamel hypomineralization of their permanent first molars. Int $\mathbf{J}$ Paediatr Dent 2002;12:24-32.

38. Croll TP. Restorative options for malformed permanentmolars in children. Compend Contin Educ Dent2000;21:676-678, 680, 682. 